\title{
CONDIÇÕES DE SAÚDE AUTO-REFERIDAS DE PROFESSORES DE UMA UNIVERSIDADE REGIONAL
}

\author{
Rosane Teresinha FONTANA a , Débora Avello PINHEIRO ${ }^{b}$
}

\section{RESUMO}

Trata-se de uma pesquisa com desenho epidemiológico transversal com o objetivo de investigar as condições de saúde auto-referidas de professores universitários e a interface com sua ocupação. Os dados foram coletados através de questionários auto aplicados a 34 professores de uma universidade regional comunitária e analisados empregando-se a estatística descritiva. A lombal gia e o cansaço foram queixas prevalentes e a exposição aos riscos biológicos são freqüentes na atividade ocupacional dos respondentes. A aprendizagem dos al unos representa a maior satisfação no trabal ho. A credita-se que o autocuidado e a valorização dos gestores e alunos à atividade acadêmica dos docentes podem contribuir para a promoção da saúde deste trabal hador.

D escritores: D ocentes. Saúde do trabal hador. Processo saúde-doença. R iscos ocupacionais.

\section{RESUMEN}

E sta es una investigación de diseño de corte transversal para investigar las condiciones de salud auto-referidas de los profesores universitarios y la interacción con su ocupación. L os datos fueron recolectados a través de cuestionario aplicado a 34 profesores de una universidad regional comunitaria y analizados utilizando estadística descriptiva. EI dolor lumbar y la fatiga fueron frecuentes las quejas y la exposición a los riesgos biológicos son frecuentes de exposición ocupacional de los encuestados. E I apr endizaje de los estudiantes es la mayor satisfacción laboral. Se cree que el auto-cuidado y la val orización de los directivos y los estudiantes en la actividad académica de los profesores pueden contribuir a la promoción de la salud de los trabajadores.

D escriptores: D ocentes. Salud laboral. P roceso salud-enfermedad. Ri iesgos laborales.

T ítulo: Condiciones de auto-reporte de salud de los profesores de una universidad regional.

\section{ABST RACT}

This is a survey of cross-sectional epidemiological design that aims to investigate the conditions of self- reported health of university professors and the interface with their occupation. D ata w ere collected via self applied questionnaires given to 34 teachers from a regional community university and analyz ed with the use of descriptive statistics. $L$ ow back pain and fatigue w erethe predominant complaints and exposure to biological haz ards arefrequent in theoccupational activities of the respondents. Student learning represents theg reatest satisfaction for theseprofessionals. It is believed that the care and recover y of managers and students in relation to the academic practice of the faculty may contribute to the promotion of health of workers.

D escriptors: F aculty. 0 ccupational health. $H$ ealth- disease process. 0 ccupational risks.

T itle: Conditions of self-reported health of teachers from a regional university.

\footnotetext{
a M estre em E nfer magem, D ocente dos Cursos de G raduação e Pós-G raduação da U niversidade Regional Integrada do Alto U ruguai e das M issões (URI) - Campus Santo Ângelo, M embro do G rupo de Estudos e Pesquisas em Enfermagem Saúde e E ducação (GE PE SE/ U RI), Santo Ângelo, Rio Grande do Sul, Brasil.

${ }^{b}$ Enfermeira graduada pela U RI - Campus Santo Ângelo, Rio G rande do Sul, Brasil.
} 


\section{INT RODUÇÃO}

Ao longo do tempo, os professores vêm sofrendo transformações no seu cotidiano, em decorrência das novas tecnologias, mudanças no sistema educacional e nas formas de organização do seu trabal ho. Com isso, a rotina do seu trabalho modificou, as exigências socioeconômicas aumentaram o que favorece a exposição deste trabalhador a cargas de trabalho fatigantes e a dispor de menos tempo para o lazer e o convívio familiar, tornando-o vulnerável ao sofrimento e ao adoecimento.

0 sofrimento distingue o campo que demarca a saúde da doença. Q uando a relação do trabal hador com a organização do trabalho é bloqueada inicia-se um processo de sofrimento. A energia que não pode ser atenuada no exercício laboral se acumula no psíquico, causando desprazer e tensão. Considerando que tal energia não pode ficar acumulada por muito tempo, findando-se as capacidades de contensão, ela se reflete no corpo ${ }^{(1)}$.

Sabe-se que fatores inerentes ao próprio processo/ organização do trabal ho docente podem funcionar como estressores, precipitar doenças e/ ou gerar insatisfações, tais como a pressão do tempo, decorrente das metas de produtividade, por excessivas demandas de cursos e atualizações; conflitos nas relações hierárquicas; ausência de autonomia decisória; dificuldades de contato com colegas durante a jornada de trabal ho e, desval orização e desrespeito por parte dos alunos ${ }^{(2,3)}$, interferindo na qualidade de vida e de trabal ho deste sujeito.

Com a finalidade de avaliar as condições de trabal ho e saúde dos trabal hadores do ensino privado no estado do R io Grande do Sul (BR), o D epartamento Intersindical de Estudos e Pesquisa de Saúde e dos A mbientes de Trabal ho (DIESAT) investigou mais de 1.600 professores do ensino fundamental, médio e superior que trabal ham em instituições privadas do estado e demonstrou que os professores têm dificuldades para dormir, sentemse irritados e ansiosos. D ores, rouquidão e perda de voz, doenças ósteoarticulares, enxaquecas e gastrites foram as principais queixas de adoecimento decorrente do trabal ho e a grande maioria dos entrevistados referiu cansaço e esgotamento nos últimos seis meses. Foi concluído que os principais fatores prejudiciais a saúde dos professores no ensino privado estão relacionados à organização e às relações no local de trabalho(4).
É válido salientar que, em geral, o professor apela a esforços extras para atualizar conhecimentos e instrumentalizar-se ás novas tecnologias que suas funções didáticas e pedagógicas requerem, cumprindo uma jor nada que excede aquela presumida em seu contrato de trabalho(5). Suas atividades intra ou extraclasse requerem condições físicas e psicológicas, pois envolvem esforço físico, caracterizado seja pela necessidade de força e resistência para a busca de informações, para o transporte de materiais seja para ficar sentado ou em pé por tempo prolongado orientando, escrevendo, ensinando, além de esforço mental demandado para as exigências cognitivas, o que envolve gasto energético e gera alterações fisiológicas ${ }^{(3)}$.

Sendo assim, esta investigação justifica-se quando considera que conhecer ag ravos decorrentes do trabalho pode contribuir na prevenção do sofrimento e do adoecimento a este relacionado, além de capilarizar saberes que venham a auxiliar na sensibilização de gestores acerca da seriedade que o tema requer, e, por conseguinte, na mel horia das condições de vida do trabal hador docente.

Considerando que o conceito de saúde não e só ausência de doença, mas também a adaptação do sujeito com o ambiente em que vive, incluindo o trabal ho, objetivou-se investigar as condições de saúde auto-referidas de professores universitários e a interface com sua ocupação.

\section{MATERIAIS E MÉTODOS}

Pesquisa com desenho transver sal. Para a coleta de dados foi oferecido um questionário a todos os 37 docentes do Departamento de Ciências da Saúde de uma universidade regional, de fins nãolucrativos e pessoa jurídica de direito privado, situada na região nor oeste do estado do Rio $\mathrm{G}$ rande do Sul; responderam ao questionário 34 sujeitos. As perguntas envolveram a investigação das condições de trabalho e saúde, incluindo queixas de morbidade e exposição a riscos ocupacionais. Os critérios de inclusão para a participação dos profissionais na pesquisa foram: ser professor universitário, em atividade, do departamento de Ciências da Saúde; ter formação em educação física, enfermagem e/ ou farmácia, cursos de Saúde mantidos pela referida universidade e aceitar participar da pesquisa. Foram critérios de exclusão: estar afastado por licença; ser professor vinculado a outro 
departamento ou com outra for mação que não seja enfer magem, educação física e farmácia.

Os dados foram coletados no segundo semestre de 2009, mediante convite à participação e agendamento com os professores para o recolhimento dos questionários, nas dependências da universidade.

Os dados obtidos a partir dos questionários auto-aplicáveis foram tratados utilizando-se como recurso a estatística descritiva, por meio do uso de medidas de frequência das variáveis. 0 estudo não teve a intenção de associar variáveis.

Para a realização deste estudo for am respeitados os aspectos éticos para a pesquisa envolvendo seres humanos estabel ecidos pela Resolução 196/ 96 do Conselho N acional da Saúde ${ }^{(6)}$. 0 projeto foi aprovado no Comitê de Ética da referida universidade, sob registro 052-04/ 09. Foi anexado junto ao questionário um Termo de Consentimento Livre e Esclarecido e ao coordenador de área do conhecimento em Ciências da Saúde foi encaminhado um T er mo de Ciência, solicitando sua autorização para a pesquisa.

\section{RESULTADOS E DISCUSSÃO}

Participaram da pesquisa 34 professores do D epartamento de Ciências da Saúde, de um total de 37 professores lotados nesta área do conhecimento.

\section{Caracterização dos sujeitos}

Dos 34 professores lotados no Departamento de Ciências da Saúde e que responderam o questionário 41,2\% trabalham, predominantemente, no Curso de Enfer magem, 35,3\% no Curso de Farmácia e 23,5\% no Curso de E ducação Física. D estes, são do sexo feminino $62 \%$. E m relação ao estado civil $82,4 \%$ são casados. A faixa etária da população estudada corresponde a uma média de idade de 40,6 anos. Quanto à carga horária na universidade $76,4 \%$ trabal ham até 30 horas semanais e $23,6 \%$ até 40 horas semanais; $22 \%$ cursam pós-graduação scricto sensu.

D os respondentes, 58,9\% possuem outro vínculo empregatício. T rabal har mais de 40 horas por semana e assumir jornadas múltiplas de trabalho podem ser fatores preditivos de cansaço e desgaste, situação que aproxima o professor do proletário, alienado ao produto do seu trabalho, pois passa a vender a força deste trabal ho e a produzi-lo "em série", sob intermináveis jornadas laborais ${ }^{(5)}$.

Em relação a variável Índice de M assa Corporal (IM C) o grupo apresentou um valor médio de $24,1 \mathrm{~kg} / \mathrm{m}^{2}$, o que demonstra parâmetros ideais de peso para sua estatura e compatível com a literatura que é de 18,5 a 24,99kg/ m/2(7). Quanto à realização de atividades físicas, $79 \%$ real izam atividade física, sendo a caminhada a mais relatada. Há evidencias epidemiológicas da inter-relação saúde e atividades físicas, que, se praticados de forma regular podem ter benefícios para a saúde ${ }^{(8)}$. E $\mathrm{m}$ relação à alimentação, 44\% dos respondentes a considera pobre em gorduras.

\section{Condições de saúde e trabalho}

Dentre os $59 \%$ que consideram sua saúde de regular a boa, as maiores queixas referem-se às dores. As dores mais freqüentes, decorrentes da ocupação, referidas pelos professores foram lombalgia (26\%), cefaléia (19,3\%), artral gias (16,1\%), cervical gia $(16,1 \%)$ e dor nos membros inferiores (13\%). A dor, para os pesquisados está associada aos longos períodos em pé e às tensões. H ouve relato de mais de um tipo de dor.

0 enfrentamento da dor, de acordo com os pesquisados é feito através de alongamento, massagem, acupuntura, homeopatia e uso de medicamentos como antiinflamatórios e analgésicos. Semel hante aos dados deste estudo, dentre as dores mais presentes nas pesquisas está a lombal gia e a dor nos membros inferiores e superiores ${ }^{(2,4,5)}$. A lém da dor, agravos como cansaço (33,3\%) evarizes (12\%) foram queixas citadas pelos depoentes. Permanecer em posição ortostática por longos períodos, carregar excesso de peso em material didático e trabalhar sob condições ergonomicamente inadequadas podem justificar tais agravos $\mathrm{S}^{(2,5)}$.

A maioria dos depoentes $(67,6 \%)$ não referenciou sofrimento psíquico, sob esta denominação, porém queixas de estresse (23\%) e irritabilidade $(14,2 \%)$ foram citadas como agravos decorrentes da ocupação. D os $26,4 \%$ que informaram sofrimento psíquico, prevalece a ansiedade $(63,6 \%)$ e a depressão $(18,1 \%)$, atribuídas à sobrecarga de trabaIho, aos múltiplos compromissos acadêmicos, à carga horária, à pressão dos gestores e ao estresse. Os sujeitos enfrentam o sofrimento psíquico através de ter apia, medicações e atividades de lazer. 
A lém das atividades destinadas ao preparo de aulas, atendimento de alunos, avaliação, lançamento de notas/ freqüência no sistema, a sobrecarga de trabalho do professor advém dos afazeres desenvolvidos nos fins de semana, nos períodos de interrupção do ano letivo, ou seja, nos momentos destinados ao descanso e lazer. N esses momentos, para dar conta da sobrecarga de atividades, preparam projetos, preenchem formulários, escrevem artigos ou relatórios de pesquisa, lêem textos ${ }^{(5)}$, entre outras atividades. Sabe-se que o aumento da produção científica docente está sendo muito estimulado pelas instituições reguladoras da pós-graduação e de fomento à pesquisa, o que possibilita ao professor que ele se mantenha em programas de pós-graduação e consiga, consequentemente, financiamentos para pesquisas.

Por outro lado, esta busca incessante de aumento da produção acaba desenvolvendo uma espécie de competição entre os próprios professores, e os conduz ao cansaço, estresse e, muitas vezes, à frustração, enquadrando o trabalho docente à lógica do mercado capitalista, ao se hastear um sistema de avaliação produtiva, sobre o qual se imprime uma valoração quantitativa em detrimento da qualidade ${ }^{(5)}$ e o molda como um fator preditivo de sofrimento e adoecimento.

Estudos apontam que os professores universitários ou do ensino médio e fundamental são frequentemente acometidos por sofrimento psíquico tais como cansaço mental, "nervosismo", insônia, ansiedade, depressão e estresse $e^{(2-5,9-11)}$. N o presente estudo, embora não prevalente, a porcentagem apresentada preocupa na medida em que os distúrbios mentais são uma das causas preval entes de afastamento/ aposentadoria decorrentes de problemas de saúde entre os professores ${ }^{(12,13)}$. Considerando que a $U$ niversidade em estudo não possui a figura do professor substituto, os afastamentos geram sobrecarga a outro trabalhador.

E $m$ relação aos riscos ocupacionais, a maioria $(73,5 \%)$ dos docentes pesquisados os identifica no seu cotidiano. Segundo a Organização Panamericana de Saúde ${ }^{(14)}$, os riscos físicos são decorrentes do ruído, vibração, radiação ionizante e nãoionizante, temperaturas extremas (frio e calor), pressão atmosférica anormal, entre outros. 0 ruído e a vibração excessivos, a radiação ionizante e não-ionizante, temperaturas extremas (frio e ca(or), pressão atmosférica anormal, entre outros são considerados riscos físicos. Os riscos químicos re- ferem-se aos agentes e substâncias químicas, sob a forma líquida, gasosa ou de partículas e poeiras minerais e vegetais. Os riscos biológicos estão associados a vírus, bactérias, parasitas, Os riscos ergonômicos e psicossociais decorrem da organização e gestão do trabalho, como, por exemplo: da utilização de equipamentos, máquinas e mobiliário inadequados, levando a posturas e posições incorretas; locais adaptados com más condições de iluminação, ventilação e de conforto para os trabaIhadores; trabal ho em turnos e noturno; monotonia ou ritmo de trabal ho excessivo, exigências de produtividade, relações de trabalho autoritárias, fal has no treinamento e supervisão dos trabal hadores, reuniões de grupo e com a chefia, entre outros. Os riscos mecânicos e de acidentes são aqueles ligados à falta de proteção do trabalhador, falta de equipamentos de proteção individual, aparel hamento inadequado, arranjo físico, ordem e limpeza do ambiente de trabal ho, sinal ização, rotulagem de produtos e outros que podem levar a acidentes do trabalho.

A exposição ao risco biológico foi o mais citado, correspondendo a $29 \%$. Os docentes expõemse a microrganismos e fluidos decorrentes das aulas práticas, nos campos de ensino em hospitais, laboratórios, unidades básicas de saúde, visitas domiciliares, entre outros.

D oenças e acidentes relacionados aos fluidos biológicos a que estão expostos os trabal hadores da saúde, tais como a síndrome da imunodeficiência adquirida, a hepatite e a tuberculose, classificadas como doenças emergentes e (re)emergentes e sob novos comportamentos epidemiológicos, desafiam e preocupam estudiosos da ár ea pelos riscos de infecção e consequente morbidade.

Os riscos físicos relatados perfazem $19 \%$ e são ocasionados pela exposição ao ruído interno e exter no ao ambiente de trabalho e às temperaturas extremas (frio e calor), principalmente, dado semelhante aos encontrados em outros estudos ${ }^{(2,3,5)}$.

Numa investigação acerca do conforto acústico de 37 salas de aula e do desempenho vocal de 37 professores de uma U niver sidade foi concluído que $97,3 \%$ das salas aval iadas encontravam-se fora dos limites de conforto acústico aceitáveis pela N BR 10.152, o que obriga o professor a aumentar a intensidade vocal no mínimo em +10 ou $+20 \mathrm{~dB}$, aumentando o esforço vocal de, aproximadamente, até $30 \mathrm{~dB}$ (A) para sobrepor a voz ao ruído de fundo. A lém de ser uma fonte de estresse, o ruído provoca rea- 
ções físicas e psíquicas, tais como perda da concentração, aumento da frequência cardíaca e dificuldade de conciliar o sono. D esgaste vocal, dores de garganta, voz rouca dores de cabeça e estresse são sintomas citados por professores decorrentes do desgaste físico provocado pelo ruído em sala de aula(15).

D entre os sujeitos pesquisados neste estudo, $26,4 \%$ referiu dificuldade na emissão de voz decorrente do trabalho e atribuída ao seu uso excessivo e pela necessidade de aumentar o tom em virtude dos ruídos ocasionados por barulho interno e exter no à sala de aula ou decorrente de acústica inadequada das mesmas. É válido referir que as salas não possuem microfone e, em muitas turmas há mais de 40 alunos. Este problema é enfrentado mediante a ingestão de bastante líquido, o uso de exercícios vocais e de descanso das cordas vocais, evitando falar caso não seja necessário. I mportante é salientar que os distúrbios vocais são frequentes em professores ${ }^{(2,5)}$ e causa significativa de rouquidão, perdas da voz e afastamentos de suas atividades $^{(4,10,16)}$.

Riscos químicos corresponderam a $17 \%$ das respostas, pelo contato com substâncias químicas usadas em atividades práticas, tais como esterilizantes, desinfetantes, solventes, ácidos, gases, entre outras. Não foi intenção do estudo, associar a atividade à exposição, o que limita a generalização do estudo, considerando que professores dos cursos de farmácia e de enfermagem, por conta das atividades inerentes à profissão, estão naturalmente mais expostos aos riscos químicos e biológicos.

U m estudo realizado em Connecticut (E stados U nidos) demonstrou alguma evidência do aumento do risco de Linfoma N ão-H odgkin decorrente da exposição ocupacional a formaldeído, solventes, carbonos e benzeno e, concluiu uma potencial associação entre a exposição ocupacional a solventes orgânicos e o risco deste tipo de linfoma entre as mulheres ${ }^{(17)}$.

É valido salientar que, em campos de prática os enfermeiros e farmacêuticos docentes estão sob a mesma condição de exposição a riscos que os profissionais da área que trabalham em atividades não docentes. 0 contato constante com drogas citostáticas e antibióticas; a exposição a gases anestésicos, vapores de formaldeído/glutaraldeído, por exemplo, são riscos químicos que causam danos expressivos à saúde do profissional que as manuseiam, tais como anormalidades cromossômicas, derma- tites, neoplasias, intoxicações, alergias, alterações dos sistemas reprodutivos, urinários, entre outros ${ }^{(18,19)}$, assim como o contato com fluidos orgânicos são riscos biológicos que podem predispor às infecções, tanto nas atividades práticas docentes como naquel as assistenciais ou de natureza farmacológica e/ ou de análise bioquímica.

U ma minoria dos sujeitos referiu alergia (14,7\%), sendo a exposição ao pó de giz o principal fator desencadeante naqueles que a citaram. 0 enfrentamento desse agravo se dá evitando o quadro de giz e no uso de anti-histamínicos. Sabe-se que a necessidade do contato com esse mineral, pode derivar da insuficiência de recursos de natureza audiovisual e/ ou de quadros brancos em que a escrita é feita com caneta, resultando em parcas alternativas do professor ao uso de outras formas didáticas para a condução de suas aulas, o que favorece a exposição.

Dentre os riscos psicossociais, a violência psicológica por parte de alunos e de gestores foi descrita por $11 \%$ dos docentes e 0 trabal ho excessivo correspondeu a $6 \%$. Os riscos ergonômicos corresponderam a $13 \%$ dos riscos citados, devido ao mobiliário inadequado, más condições de iluminação, ventilação e de conforto para os trabal hadores. R iscos mecânicos e de acidentes foi relatado por $5 \%$ dos sujeitos. M ais de um risco foi citado por um pesquisado.

E mbora não citados nesta categoria pelos docentes, a partir da análise dos dados pode-se inferir que riscos ergonômicos e psicossociais são potencialmente significativos, considerando que a prevalência das queixas relacionadas às suas condições de saúde está pautada na categoria dos agravos osteomusculares em decorrência de longos períodos em posição ortostática, além de cansaço e tensões decorrentes do trabal ho.

Pesquisas demonstram que os riscos físicos que mais expõem os professores, de acordo com sua percepção, são ruído e ventilação deficientes nas sal as de aula; a exposição ao pó de giz, a poeira e os produtos químicos são os riscos químicos mais citados; os riscos ergonômicos preval entes referemsea manter-se em pé por longos períodos, escrever no quadro de giz e permanecer em posição inadequada do corpo junto ao peso excessivo dos materiais do tipo livros, pastas e equipamento de audiovisual que car regam e, os riscos biológicos mais referidos são a exposição a microorganismos em decorrência das práticas ${ }^{(2,3)}$, resultados que se aproximam dos encontrados neste estudo. 
E $m$ relação às condições de trabalho, 82,3\% as considera satisfatórias. Quanto à satisfação no processo de trabalho, 97,5\% referiram 0 aprendizado e o interesse dos al unos como maior fonte de satisfação, o que corrobora com outros estudos realizados em universidades privadas e públicas e demonstra o comprometimento do professor com a formação discente $e^{(3,20)}$.

Além disso, outros fatores geradores de satisfação foram citados por grande parte dos sujeitos, tais como: apropriada estrutura física e infra-estrutura, bons laboratórios para a prática do ensino, organização da universidade, boas relações interpessoais e salário acima da média da profissão. As insatisfações apontadas decorrem da situação dos campos de prática externos à universidade, considerados como ambientes deficitários porque carece de conforto e praticidade que incluem sala arejada, armários e informatização. Foram citados como desagrado os ruídos externos decorrentes de obras de manutenção ou limpeza e, a ventilação e o arranjo acústico/ físico inadequado das salas de aula e/ ou dos professores, em conformidade com outros estudos sobre o tema $a^{(2,3,5)}$.

T ambém emergiram como descontentamento a falta de interesse dos alunos e, de reconhecimento e respeito por parte de al guns gestores, dificuldades de acesso à multimídia, pouco tempo para planejamento e estudo, cargas horárias excessivas, incertezas de garantia de emprego; resultados similares a um estudo realizado em três universidades privadas ${ }^{(20)}$

Isto posto, pode-se inferir que os professores da realidade estudada, estão trabal hando sob sofrimentos, sentimentos e morbidades semel hantes a outros cenários e, que, mesmo percebendo condições laborais satisfatórias queixam-se da longa carga horária e de tempo insuficiente para estudo, por exemplo, o que denota deficiência nos recursos humanos para atender a demanda quantitativa e qualitativa de trabalho. Tendo em vista que grande parte dos professores está contratada sob o regime horista, muitas vezes aquele que possui regime de tempo integ ral, expõe-se à sobrecarga pela necessidade de envolver-se em pesquisa, ensino e extensão, al ém de atividades como participação de comissões, organização de eventos, entre outras, exigidas deste professor, por conta da redução de custos.

É oportuno salientar que os cenários públicos de ensino superior, da mesma forma, vivenciam profundos impactos estruturais, gerados por polí- ticas gover namentais a eles desfavoráveis, tais como a ameaça de perdas de direitos previdenciários e consequentes aposentadorias, muitas vezes precoce, que aliada as limitações à realização de novos concursos, resultam na diminuição de parte expressiva do corpo docente dessas instituições, com repercussões sobre a qualidade do ensino ${ }^{(5)}$ e da saúde dos professores.

É necessário, portanto, buscar condições de trabalho, sob garantias legais, que promovam a qualidade de vida dos profissionais da educação, de modo que os direitos trabal histas não sejam negligenciados em favor de um mercado capitalista e atrelado à exploração do trabal ho.

\section{CONCLUSÕES}

0 estudo revel ou que a maioria dos docentes, sofre de alguma espécie de exposição a riscos ou morbidades decorrentes do trabalho. Constatouse que a carga horária de trabalho dos docentes é longa, sendo que, muitos possuem dois empregos, o que pode explicar as significativas queixas de cansaço e lombal gia.

M elhorias nas condições de trabalho, recursos e fomentos que contribuam para a concretização digna da pesquisa, extensão e ensino, parece ser uma política que auxilia na construção de maior valorização docente, além de que, diminuir a sobrecarga de trabalho, mediante uma gestão que priorize a promoção da saúde do docente pode ser uma estratégia para a qualidade do ensino universitário.

U ma limitação do estudo encontrada foi a dificuldade de encontrar al guns professores na univer sidade, pois muitos são horistas, embora a maioria dos sujeitos tenha sido colaborativa com a pesquisa.

Sugerem-se estudos que possam contribuir para mel horar a qualidade de vida do professor, tais como pesquisas que avaliem número de turmas atendidas, a infraestrutura das sal as de aula e a relação com o processo saúde-adoecimento. Além disso, podem ser objetos de pesquisa a relação deste processo com as cargas psíquicas, o status profissional, a relação com alunos e gestores, as diferenças de gênero e sexo no processo de adoecimento e enfrentamento das adversidades, assim como os dispositivos promotores de saúde física e mental deste profissional. 


\section{REFERÊ NCIAS}

1 Dejours C, Abdoucheli E, Jaye C. Psicodinâmica do trabal ho: contribuições da E scola D ejouriana à análise da relação prazer, sofrimento e trabalho. São Paulo: Atlas; 1994

2 A raújo T M , Sena IP, Viana M A, A raújo E M . M alestar docente: avaliação de condições de trabal ho e saúde em uma instituição de ensino superior. Rev Baiana Saúde Pública. 2005;29(1):6-21.

3 L emos J C. Cargas psíquicas no trabalho e processos de saúde em professores universitários [ tese]. Florianópolis: D epartamento de Engenharia de Produção, U niversidade Federal de Santa Catarina; 2005.

4 Departamento Intersindical de Estudos e Pesquisas de Saúde e dos A mbientes de T rabal ho. Condições de trabalho e saúde dos trabalhadores do ensino privado no estado do Rio G rande do Sul [I nter net] . São Paulo; 2009 [ citado 2009 dez 20]. Disponível em: http:/ / www.sinpro-rs.org.br/ pesquisa/ PesquisaSaude 2009.pdf.

5 L ima M F E M , Lima-F ilho D 0. Condições de trabalho e saúde do/ a professor/ a universitário/ a. Ciênc Cogn [ Internet] . 2009 [ citado 2010 jan 12];14(3):62-82. Disponível em: http:/ / www.cienciasecognicao.org/ revista/ index.php/ cec/ article/ viewF ile/ 253/ 136.

6 M inistério da Saúde (BR ), Consel ho N acional de Saúde. Resolução 196, de 10 de outubro de 1996: diretrizes e nor mas regulamentadoras de pesquisa envolvendo seres humanos. Brasília (DF); 1996.

7 M inistério da Saúde (BR ). Peso ideal [ I nternet] . Brasília (D F ); 2010 [ citado 2010 jun 12] . D isponível em: http:/ / portal.saude.gov.br/ portal/ saude/ visualizar texto.cfm?idtxt=29922\&janela=1.

8 M adureira AS, Fonseca SA, M aia M F M . E stilo de vida e atividade física habitual de professores de E ducação F ísica. Rev B ras Cineantropom D esempenho H um. 2003;5(1):54-62.

9 Contaifer T RC, Bachion M M, Yoshida T, Souza JT. E stresse em professores universitários da área de saúde. Rev G aúcha E nferm. 2003;24(2):215-25.

10 Servilha EAM, Pereira PM Condições de trabalho, saúde e voz em professores universitários. Rev Ciênc M éd. 2008;17(1):21-31.

\section{Endereço da autora / Dirección del autor / Author's address:}

Rosane T eresinha Fontana

Rua Sete de Setembro, 1126

98800-000, Santo Ângelo, RS

E-mail:rfontana@urisan.tche.br
11 Lodolo D'Oria V, Bulgarini d'E Ici G, Bonomi P, Della Torre Di Valsassina M, Fasano A I, G iannella V, et al. A re teachers at risk for psychiatric disorders? Stereotypes, physiology and perspectives of a job preval ently done by women. M ed L av. 2009;100(3): 211-27.

$12 \mathrm{M}$ aguire $\mathrm{M}, \mathrm{O}^{\prime} \mathrm{C}$ onnell $\mathrm{T}$. III-health retirement of schoolteachers in the Republic of I reland. Occup M ed (L ond). 2007;57(3):191-3.

$13 \mathrm{G}$ asparini SM , Barreto SM , A ssunção A A 0 professor, as condicões de trabal ho e os efeitos sobre sua saúde. E duc Pesqui. 2005;1(2):189-99.

14 Organizacão Pan-A mericana da Saúde; M inistério da Saúde (BR ). D oenças relacionadas ao trabal ho: manual de procedimentos para os serviços de saúde. Brasília (DF); 2001.

15 G onçalves VSB, Silva LB, Coutinho AS. Ruído como agente comprometedor da inteligibilidade de fala dos professores. Prod [ I nter net]. 2009 [ citado 2010 fev 05];19(3):466-76. Disponível em: http:/ / www.scielo.br/ pdf/ prod/ v19n3/ 05.pdf.

16 Angelillo M, Di M aio G, Costa G, Angelillo N, Barillari U. Prevalence of occupational voice disorders in teachers. J Prev M ed H yg. 2009;50(1): 26-32.

17 Rong W, Yawei Z, Qing L, T heodore RH, Brian L, Shelia $\mathrm{HZ}$, et al. Occupational exposure to solvents and risk of non-hodgkin lymphoma in connecticut women. A m J E pidemiol. 2009;169(2):176-85.

18 X elegati R, Robazzi M LCC, M arziale M HP, Haas VJ. Riscos ocupacionais químicos identificados por enfermeiros que trabal ham em ambiente hospitaIar. Rev Latino-Am Enfermagem. 2006;14(2):21419.

19 Cetinkaya F, Ozturk A O, Kutluk G, E rdem E. Penicillin sensitivity among hospital nurses without a history of penicillin allergy. J Adv Nurs. 2007;58(2): 126-29.

20 Ferreira E M , Fernandes M F P, Prado C, Baptista PCP, F reitas $G$, B Bonini BB. Prazer e sofrimento no processo de trabalho do enfermeiro docente. Rev Esc E nferm U SP [ I nter net] . 2009 [ citado 2010 jan 30] 43(2):1292-6. Disponível em: http:/ / www.sciel o.br/ pdf/ reeusp/ v43nspe2/ a25v43s2.pdf

Recebido em: 21/ 03/ 2010

A provado em: 13/ 05/ 2010 